AUTHOR CORRECTION

\title{
Author Correction: PENet - a scalable deep-learning model for automated diagnosis of pulmonary embolism using volumetric CT imaging
}

Shih-Cheng Huang (D), Tanay Kothari, Imon Banerjee (D), Chris Chute, Robyn L. Ball, Norah Borus, Andrew Huang, Bhavik N. Patel (iD, Pranav Rajpurkar, Jeremy Irvin, Jared Dunnmon, Joseph Bledsoe, Katie Shpanskaya, Abhay Dhaliwal, Roham Zamanian, Andrew Y. $\mathrm{Ng}$ and Matthew P. Lungren

npj Digital Medicine (2020)3:102 ; https://doi.org/10.1038/s41746-020-00310-6

Correction to: npj Digital Medicine https://doi.org/10.1038/s41746020-0266-y, published online 24 April 2020

The original version of the published Article did not acknowledge the passing of the sixth Author, Norah Borus. To improve clarity, the Author contributions have been updated to include the following: Norah Borus was not able to review the manuscript prior to submission but she was integral to the concept and design phase of the project and contributed significantly to the codebase. Norah Borus passed away on 14th June 2019. Additionally, the second sentence in the second paragraph and the sixth sentence of the penultimate paragraph of the Discussion have been edited for clarity. The HTML and PDF versions of the Article have been corrected.

\begin{abstract}
(C) Open Access This article is licensed under a Creative Commons Attribution 4.0 International License, which permits use, sharing, adaptation, distribution and reproduction in any medium or format, as long as you give appropriate credit to the original author(s) and the source, provide a link to the Creative Commons license, and indicate if changes were made. The images or other third party material in this article are included in the article's Creative Commons license, unless indicated otherwise in a credit line to the material. If material is not included in the article's Creative Commons license and your intended use is not permitted by statutory regulation or exceeds the permitted use, you will need to obtain permission directly from the copyright holder. To view a copy of this license, visit http://creativecommons. org/licenses/by/4.0/.
\end{abstract}

(c) The Author(s) 2020 